\title{
Blood volume expansion does not explain the increase in peak oxygen uptake induced by 10 weeks of endurance training
}

\author{
$\varnothing$ yvind Skattebo ${ }^{1}$ (1) - Anders Wold Bjerring ${ }^{2,3} \cdot$ Marius Auensen $^{1} \cdot$ Sebastian Imre Sarvari ${ }^{2,3}$.

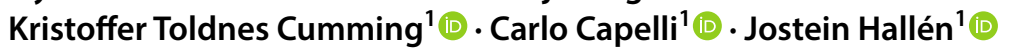

Received: 14 November 2019 / Accepted: 25 February 2020 / Published online: 14 March 2020

(c) The Author(s) 2020

\begin{abstract}
Purpose The endurance training (ET)-induced increases in peak oxygen uptake $\left(\dot{V} \mathrm{O}_{2 \text { peak }}\right)$ and cardiac output $\left(\dot{Q}_{\text {peak }}\right)$ during upright cycling are reversed to pre-ET levels after removing the training-induced increase in blood volume (BV). We hypothesised that ET-induced improvements in $\dot{V} \mathrm{O}_{2 \text { peak }}$ and $\dot{Q}_{\text {peak }}$ are preserved following phlebotomy of the BV gained with ET during supine but not during upright cycling. Arteriovenous $\mathrm{O}_{2}$ difference $\left(\mathrm{a}-\overline{\mathrm{v}} \mathrm{O}_{2} \operatorname{diff} ; \dot{V} \mathrm{O}_{2} / \dot{Q}\right)$, cardiac dimensions and muscle morphology were studied to assess their role for the $\dot{V} \mathrm{O}_{2 \text { peak }}$ improvement.

Methods Twelve untrained subjects ( $\dot{V} \mathrm{O}_{2 \text { peak }}: 44 \pm 6 \mathrm{ml} \mathrm{kg}^{-1} \mathrm{~min}^{-1}$ ) completed 10 weeks of supervised ET ( 3 sessions/ week). Echocardiography, muscle biopsies, haemoglobin mass $\left(\mathrm{Hb}_{\text {mass }}\right)$ and $\mathrm{BV}$ were assessed pre- and post-ET. $\dot{V} \mathrm{O}_{2 \text { peak }}$ and $\dot{Q}_{\text {peak }}$ during upright and supine cycling were measured pre-ET, post-ET and immediately after $\mathrm{Hb}_{\text {mass }}$ was reversed to the individual pre-ET level by phlebotomy.

Results ET increased the $\mathrm{Hb}_{\text {mass }}(3.3 \pm 2.9 \% ; P=0.005), \mathrm{BV}(3.7 \pm 5.6 \% ; P=0.044)$ and $\dot{V} \mathrm{O}_{2 \text { peak }}$ during upright and supine cycling $(11 \pm 6 \%$ and $10 \pm 8 \%$, respectively; $P \leq 0.003)$. After phlebotomy, improvements in $\dot{V} \mathrm{O}_{2 \text { peak }}$ compared with preET were preserved in both postures $(11 \pm 4 \%$ and $11 \pm 9 \% ; P \leq 0.005)$, as was $\dot{Q}_{\text {peak }}(9 \pm 14 \%$ and $9 \pm 10 \% ; P \leq 0.081)$. The increased $\dot{Q}_{\text {peak }}$ and a- $\overline{\mathrm{v}} \mathrm{O}_{2}$ diff accounted for $70 \%$ and $30 \%$ of the $\dot{V} \mathrm{O}_{2 \text { peak }}$ improvements, respectively. Markers of mitochondrial density (CS and COX-IV; $P \leq 0.007)$ and left ventricular mass $(P=0.027)$ increased.

Conclusion The ET-induced increase in $\dot{V} \mathrm{O}_{2 \text { peak }}$ was preserved despite removing the increases in $\mathrm{Hb}_{\text {mass }}$ and $\mathrm{BV}$ by phlebotomy, independent of posture. $\dot{V} \mathrm{O}_{2 \text { peak }}$ increased primarily through elevated $\dot{Q}_{\text {peak }}$ but also through a widened a- $\overline{\mathrm{v}} \mathrm{O}_{2}$ diff, potentially mediated by cardiac remodelling and mitochondrial biogenesis.
\end{abstract}

Keywords Blood volume $\cdot$ Cardiac output $\cdot$ Echocardiography $\cdot$ Haemoglobin mass $\cdot$ Maximal oxygen uptake $\cdot$ Peripheral adaptations $\cdot$ Supine cycling

\section{Abbreviations}

$\mathrm{a}-\overline{\mathrm{v}} \mathrm{O}_{2}$ diff Arteriovenous oxygen difference

$\mathrm{BV}$

CO Carbon monoxide

COX-IV Cytochrome c oxidase subunit 4

Communicated by Peter Krustrup.

Øyvind Skattebo

oyvind.skattebo@nih.no

1 Department of Physical Performance, Norwegian School of Sport Sciences, Post box 4014 Ullevål Stadion, 0806 Oslo, Norway

2 Center for Cardiological Innovation, Oslo University Hospital, Oslo, Norway

3 University of Oslo, Oslo, Norway
CS Citrate synthase

EDV End-diastolic volume

ESV End-systolic volume

ET Endurance training

HAD Hydroxyacyl-CoA dehydrogenase

[Hb] Haemoglobin concentration

$\mathrm{Hb}_{\text {mass }}$ Haemoglobin mass

HR Heart rate

$\mathrm{HR}_{\text {peak }}$ Peak heart rate

[La] Blood lactate concentration

LV Left ventricle

MCHC Mean corpuscular haemoglobin concentration

MTT Mean transit time

PV Plasma volume

$\dot{Q} \quad$ Cardiac output

$\dot{Q}_{\text {peak }} \quad$ Peak cardiac output 


$\begin{array}{ll}\text { RBCV } & \text { Red blood cell volume } \\ \text { RER }_{\text {peak }} & \text { Peak respiratory exchange ratio } \\ \text { RPE } & \text { Rating of perceived exertion } \\ \text { RV } & \text { Right ventricle } \\ \text { SD } & \text { Standard deviation } \\ \text { SV } & \text { Stroke volume } \\ \mathrm{VE}_{\text {peak }} & \text { Peak ventilation } \\ \dot{V} \mathrm{O}_{2} & \text { Oxygen uptake } \\ \dot{V O}_{2 \text { peak }} & \text { Peak oxygen uptake } \\ \dot{W}_{\text {peak }} & \text { Peak power output }\end{array}$

\section{Introduction}

During whole-body exercise, the oxidative capacity of skeletal muscle exceeds the oxygen $\left(\mathrm{O}_{2}\right)$ delivery, as illustrated by the two-fold higher mass-specific $\mathrm{O}_{2}$ delivery and peak $\mathrm{O}_{2}$ uptake $\left(\dot{V} \mathrm{O}_{2 \text { peak }}\right)$ during dynamic one-legged knee-extension compared to cycling exercise (approximately 2.5 vs $20 \mathrm{~kg}$ active muscle mass, respectively) (Boushel and Saltin 2013; Cardinale et al. 2019). Yet, endurance training (ET) induces remarkable increases in mitochondrial enzymes and capillary density, commonly improving these by $\sim 40 \%$ and $\sim 10-20 \%$ after a few months of ET, respectively (Granata et al. 2018; Klausen et al. 1981). Such adaptations are likely more important for endurance performance than $\dot{V} \mathrm{O}_{2 \text { peak }}$, but despite a long-standing debate (Bassett and Howley 2000), it remains uncertain whether $\dot{V} \mathrm{O}_{2 \text { peak }}$ is limited by central or by combined central-peripheral factors. According to the Fick equation, every change in $\dot{V} \mathrm{O}_{2 \text { peak }}$ is matched by a concomitant change in peak cardiac output $\left(\dot{Q}_{\text {peak }}\right)$ and/or arteriovenous $\mathrm{O}_{2}$ difference ( $\mathrm{a}-\overline{\mathrm{v}} \mathrm{O}_{2}$ diff). Most studies find $\dot{Q}$ peak increased following short-term ET, whereas more heterogeneous findings exist for the $\mathrm{a}-\overline{\mathrm{v}} \mathrm{O}_{2}$ diff (Montero and Diaz-Canestro 2016).

At the commencement of ET, improvements in stroke volume $(\mathrm{SV})$ and $\dot{Q}_{\text {peak }}$ are thought to be mainly facilitated by the blood volume (BV) expansion that increases venous return and preload to the heart and its filling rates (Bonne et al. 2014; Krip et al. 1997). However, cardiac remodelling has been reported already after 3 months of ET, which, together with the reduced pericardial constraints and enhanced cardiac compliance after long periods of ET (Arbab-Zadeh et al. 2014), suggests multifactorial mechanisms for the enhancement of $\dot{Q}_{\text {peak }}$ with ET (Saltin et al. 1968).

The ET-induced increase in BV can be removed by phlebotomy to assess its importance for the ET-induced changes in $\dot{Q}_{\text {peak }}$ and $\dot{V} \mathrm{O}_{2 \text { peak }}$. When using this experimental design, the $7-10 \%$ improvement in $\dot{V} \mathrm{O}_{2 \text { peak }}$ and $\dot{Q}_{\text {peak }}$ after 6 weeks of ET were reversed to pre-ET levels after phlebotomy (Bonne et al. 2014; Montero et al. 2015a). Concomitantly, no change in cardiac morphology (Bonne et al. 2014) nor in the $\mathrm{a}-\overline{\mathrm{v}} \mathrm{O}_{2}$ diff were found despite robust peripheral adaptations (Montero et al. 2015a). Therefore, the authors suggested that the improvement in $\dot{V} \mathrm{O}_{2 \text { peak }}$ was explained by increased $\dot{Q}_{\text {peak }}$ attributed to the BV expansion alone. However, acute hypovolemia due to phlebotomy may increase the sympathetic tone leading to arteriolar and venous constriction (Fortrat et al. 1998; Zollei et al. 2004) and offset an ET-induced drop in peripheral vascular resistance in these studies. In this context, reduced $\mathrm{BV}$ and impaired haemodynamic control after bed rest can lead to a reduction in $\dot{Q}_{\text {peak }}$ and $\dot{V} \mathrm{O}_{2 \text { peak }}$ during upright cycling (Saltin et al. 1968), which is reversed when measured during supine cycling (Bringard et al. 2010) due to gravitational effects on central BV, preload and thus SV (Warburton et al. 2002). The supine position increases the central venous pressure and the baroreflex loading compared to the upright position (Ray et al. 1993), thus potentially avoiding increases in sympathetic tone and total peripheral resistance in the face of reduced $\mathrm{BV}$.

We investigated the importance of the ET-induced increases in haemoglobin mass $\left(\mathrm{Hb}_{\text {mass }}\right)$ and $\mathrm{BV}$ for the changes in $\dot{V} \mathrm{O}_{2 \text { peak }}$ and $\dot{Q}_{\text {peak }}$. Maximal exercise was conducted before and after removing an amount of blood corresponding to the measured individual increase in $\mathrm{Hb}_{\text {mass }}$ induced by ET. We hypothesised that the increases in $\dot{V}$ $\mathrm{O}_{2 \text { peak }}$ and $\dot{Q}_{\text {peak }}$ would return to pre-ET levels after phlebotomy during upright cycling but remain elevated during supine cycling owing to improved venous return. Furthermore, we hypothesised that the change in $\dot{V} \mathrm{O}_{2 \text { peak }}$ is mostly facilitated by elevated $\dot{Q}_{\text {peak }}$, but also by a widened a- $\overline{\mathrm{v}} \mathrm{O}_{2}$ diff. Potential mechanisms for the changes in a-v $\mathrm{O}_{2}$ diff and $\dot{Q}_{\text {peak }}$ were studied in muscle biopsies (capillarisation and mitochondrial enzymes) and by echocardiography, respectively.

\section{Materials and methods}

\section{Ethical approval}

The study was approved by the Ethics Committee of the Norwegian School of Sport Sciences (ref. 13-220817) and The Norwegian Centre for Research Data (ref. 55151). Oral and written informed consents were obtained from all subjects before the start of this investigation, which was carried out in accordance with the Declaration of Helsinki.

\section{Subjects}

Twelve untrained subjects, defined as conducting $\leq 1 \mathrm{ET}$ session per week during the previous year, were recruited and completed the ET period ( $7 \hat{\sigma}$; age: $29.2 \pm 5.9$ years; weight: $72.4 \pm 13.1 \mathrm{~kg}$; height: $1.75 \pm 0.11 \mathrm{~m}$; body fat: $27 \pm 5 \% ; \dot{V} \mathrm{O}_{2 \text { peak }}: 44.2 \pm 5.9 \mathrm{ml} \mathrm{kg}^{-1} \mathrm{~min}^{-1}$ ). One subject performed all tests except the phlebotomy procedure and 
the post-phlebotomy testing. Therefore, data from this individual were used only when presenting individual responses and the muscle biopsy analyses. All subjects were nonsmokers and reported no contraindications to ET or maximal exercise testing.

\section{Experimental design}

The experimental design is summarised in Fig. 1. Before and after 10 weeks of $\mathrm{ET}, \mathrm{Hb}_{\text {mass }}, \mathrm{BV}$, body composition and cardiac dimensions were assessed, and a biopsy from the $m$. vastus lateralis was obtained under resting conditions. Maximal exercise testing was performed during upright and supine cycling before and after ET as well as directly after removing the BV necessary to counteract the individual increase in $\mathrm{Hb}_{\text {mass }}$ elicited by the ET. Before pre-ET measurements, all subjects were familiarised with supine cycling (two sessions) and maximal exercise during upright cycling.

\section{Exercise training}

During the 10-week ET period, the subjects underwent three supervised training sessions per week. Session 1 consisted of $60 \mathrm{~min}$ of continuous exercise between $70-80 \%$ of peak heart rate $\left(\mathrm{HR}_{\text {peak }}\right)$ (Fig. 2a). Session 2 included $4 \times 8 \mathrm{~min}$ intervals with a target intensity between $85-90 \%$ of $\mathrm{HR}_{\text {peak }}$ (Fig. 2b). Lastly, session 3 consisted of 4-6×4 min intervals with a target intensity $\geq 90 \%$ of $\mathrm{HR}_{\text {peak }}$ (four repetitions in weeks $1-3,5$ repetitions in weeks $4-6$, and six repetitions in weeks 7-9; Fig. 2c). The intervals were interspersed by 3 or 2 min active recovery at $\sim 70 \%$ of $\mathrm{HR}_{\text {peak }}$, respectively. A short tapering was performed in week 10 to maximise performance during the post-ET testing. The continuous session was shortened to $40 \mathrm{~min}$, and the number of repetitions during the 8 and 4 min intervals were reduced to three and four repetitions, respectively. All subjects conducted 27-30 ET sessions (compliance: $94.4 \pm 3.6 \%$ ).

\section{Measurements and procedures}

\section{Body composition}

Body composition was assessed by dual-energy X-ray absorptiometry (Lunar iDXA, enCORE software version 17; GE Healthcare, Chicago, IL, USA) after overnight fasting.

\section{Haematology and blood withdrawal}

Blood from an antecubital vein was collected in the morning under standardised, seated conditions. Haematological variables were analysed for EDTA blood ( $3 \mathrm{ml}$; BD, Franklin Lakes, NJ, USA) using a Sysmex XN-9000 (Sysmex, Kobe, Japan). Serum samples (SST II Advance $5 \mathrm{ml}$; BD) were placed at room temperature for coagulation $(30 \mathrm{~min})$, centrifuged at $1500 \mathrm{G}$ for $10 \mathrm{~min}$ and stored at $4{ }^{\circ} \mathrm{C}$ until analysed for ferritin concentration (Advia Chemistry XPT; Siemens Healthineers, Erlangen, Germany).

$\mathrm{Hb}_{\text {mass }}$ was measured in duplicate on separate days using a carbon monoxide $(\mathrm{CO})$ rebreathing method (Prommer and Schmidt 2007; Schmidt and Prommer 2005). First, the subjects rested seated for $10 \mathrm{~min}$, followed by capillary blood sampling in two $125-\mu$ l pre-heparinised tubes (Clinitubes; Radiometer, Copenhagen, Denmark) from a pre-heated fingertip. The subjects then inhaled a bolus of $1.0(+)$ or

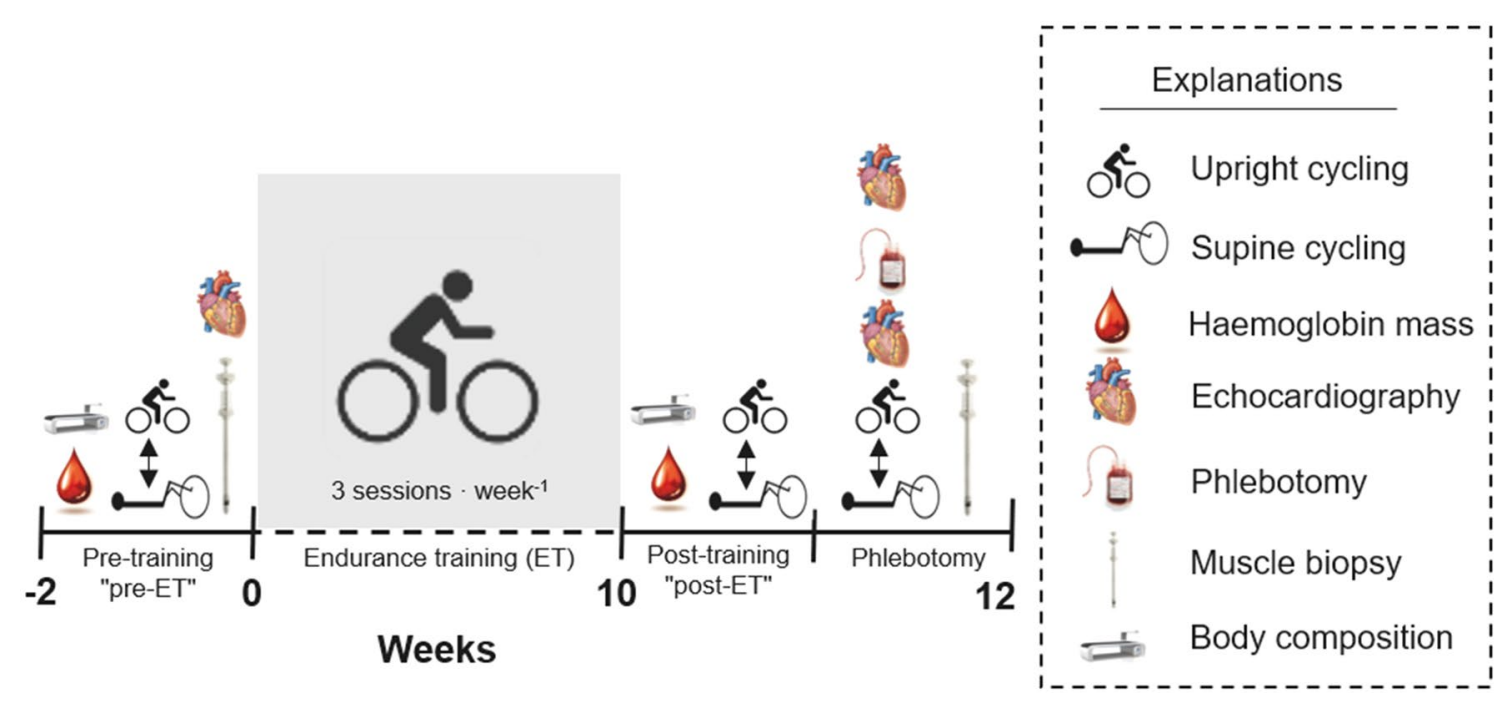

Fig. 1 The experimental design of the study. During the phlebotomy trial, echocardiography was conducted first (the post-ET echocardiography), following which the subjects were phlebotomised. This was followed by a second echocardiography. The first of two cycling exercises was initiated precisely 45 min after phlebotomy 

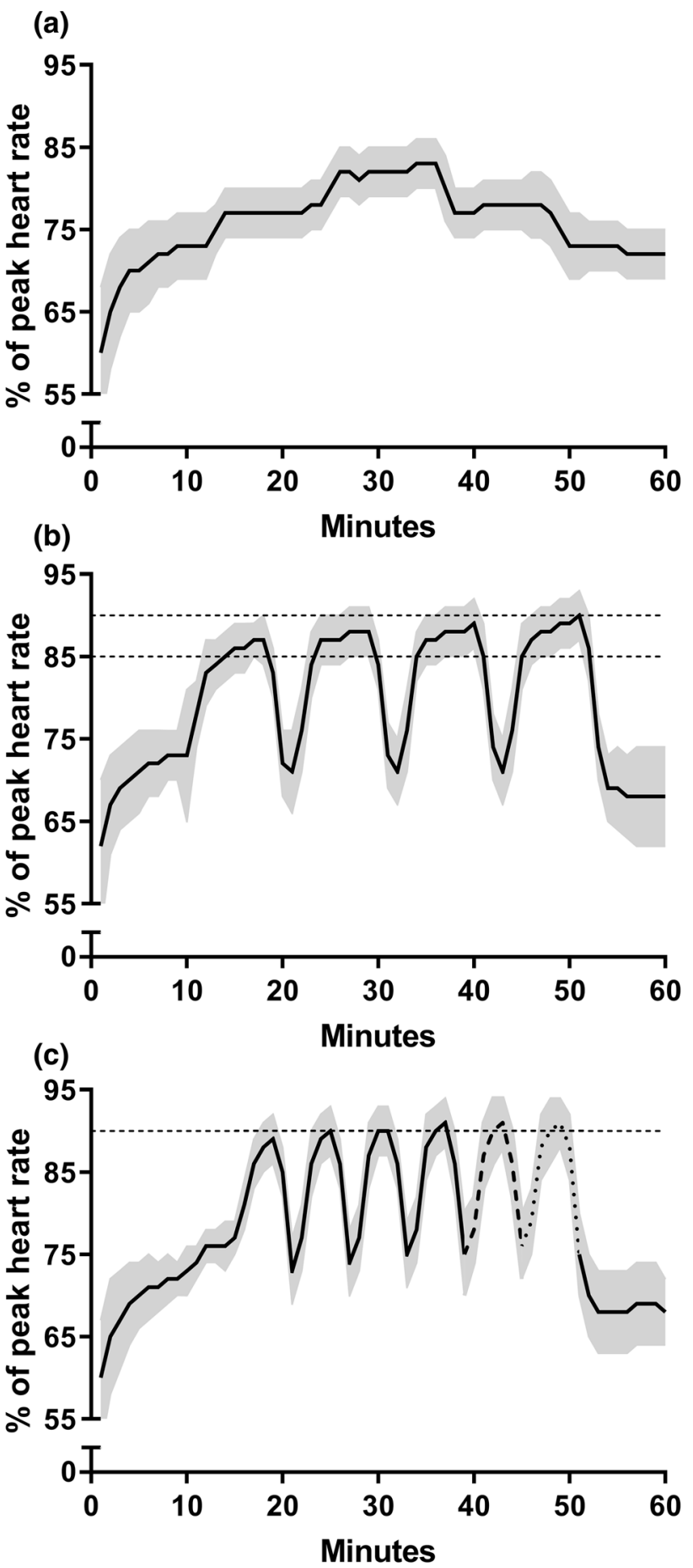

Fig. 2 Percentage of peak heart rate during continuous moderate intensity (a); 8-min interval (b); and 4-min interval (c) sessions conducted during the training period. The black lines and the greyshaded areas denote their mean values and standard deviations, respectively

1.2 (ð) $\mathrm{ml}$ per kg body weight of $99.97 \%$ chemically pure CO (AGA Norge, Oslo, Norway) administered via a 100$\mathrm{ml}$ plastic syringe (Omnifix; Braun, Kronberg im Taunus,
Germany) to a spirometer (Blood tec GmbH, Germany). In this closed circuit, the $\mathrm{CO}$ was rebreathed for 2 min together with 31 of pure $\mathrm{O}_{2}$ (AGA Norge) while checking for leakages using a $\mathrm{CO}$ analyser (Draeger, Lübeck, Germany). Two capillary blood samples were collected, 6 and 8 min after the administration of $\mathrm{CO}$. All blood samples were immediately analysed in duplicate for percent carboxyhaemoglobin using an ABL80 CO-OX FLEX (Radiometer). After rebreathing, the $\mathrm{CO}$ not absorbed by the body was calculated by multiplying the $\mathrm{CO}$ concentration of the rebreathing bag by the bag volume and the subject's estimated residual lung volume (Miller et al. 1998). The CO exhaled between the time point of disconnecting from the spirometer to the blood sampling was estimated by multiplying the difference in end-tidal $\mathrm{CO}$ concentration before and after rebreathing by the estimated alveolar ventilation (West 2008). The $\mathrm{Hb}_{\text {mass }}$ was calculated by dilution of CO in blood (Schmidt and Prommer 2005) with correction for loss of $\mathrm{CO}$ to myoglobin $(0.3 \%$ of the administered CO per minute) (Prommer and Schmidt 2007). The coefficient of variation of the duplicate $\mathrm{Hb}_{\text {mass }}$ determinations, expressed as the percent typical error (standard deviation of the difference scores $/ \sqrt{2}$ ), was $1.10 \%$. To derive intravascular volumes (BV; red blood cell volume, RBCV; plasma volume, PV), the formulae given by Siebenmann et al. (1985) were used with no correction for venous to whole-body haematocrit.

The phlebotomy trial was conducted $3.9 \pm 2.2$ days after the post-ET trial. A BV equal to each individual's ETinduced increase in $\mathrm{Hb}_{\text {mass }}\left(\Delta \mathrm{Hb}_{\text {mass }} /[\mathrm{Hb}]\right)$ was removed by phlebotomy via an $18 \mathrm{G}$ catheter (BD) indwelling in an antecubital vein. Immediately after the phlebotomy, echocardiography was conducted, followed by exercise testing starting $45 \mathrm{~min}$ after the phlebotomy.

\section{Exercise testing}

Upright and supine cycling were conducted in random counterbalanced order on the same day, interspersed by $45 \mathrm{~min}$ of passive rest. During upright cycling (Excalibur Sport; Lode B.V., Groningen, The Netherlands), the test started with a 3-min resting measurement while seated on the bike. Thereafter, three 5-min submaximal workloads ( $ぇ 50-150 \mathrm{~W}$, ㅇ $50-100 \mathrm{~W}$ ) were conducted directly followed by a maximal test with step-increments of $25 \mathrm{~W}$ every minute until exhaustion. The mean workload during the last $60 \mathrm{~s}$ was defined as the peak power output $\left(\dot{W}_{\text {peak }}\right)$. During supine cycling (Angio 2000; Lode B.V.), the subjects were fastened with a four-point harness lying on a bench. The axis of rotation and thus the legs were raised $\sim 20 \mathrm{~cm}$ above the heart. The structure of the protocol was similar to upright cycling, with the submaximal workloads ( $\delta$ 50-100 W, o 50-75 W) followed by step-increments of $20 \mathrm{~W}$ every minute. After reaching exhaustion, the subjects cycled at $40-50 \mathrm{~W}$ for $5 \mathrm{~min}$ to 
speed up their recovery. $\dot{V} \mathrm{O}_{2}$ was measured over the last 2.5 min at each submaximal stage and continuously during the resting measurements and incremental tests, using open-circuit indirect calorimetry with a mixing chamber (Oxycon Pro; Jaeger Instrument, Friedberg, Germany) (Foss and Hallén 2005). Before each test, the gas analysers and flow transducer were calibrated according to the instruction manual.

SV, HR and $\dot{Q}$ were continuously monitored by impedance cardiography and an integrated electrocardiogram using a PhysioFlow Q-link device (Manatec Biomedical, Paris, France). This method is evaluated against the direct Fick method (Charloux et al. 2000; Richard et al. 2001; Siebenmann et al. 2015) and uses the cyclic variations in transthoracic impedance during the cardiac cycle to estimate $\mathrm{SV}$, as these pulsatile variations represent the changes in volume and velocity of the aortic BV (Charloux et al. 2000; Richard et al. 2001). Six electrodes (PF-50; Manatec Biomedical) were placed on each subject's neck, chest and back after the skin was cleaned with alcohol and rubbed with an abrasive ECG preparation gel (Custo prep; Custo med, Ottobrunn, Germany). Equal placement of electrodes in all tests was ensured by tracking their positions on transparent plastic sheets according to skin and anatomical landmarks. The subjects wore a tight mesh t-shirt to avoid displacement of the electrodes and their attached leads. A fan was placed in front of the subjects for heat dissipation to counteract the accumulation of sweat during exercise, to ensure that the electrodes maintained adhesiveness throughout the test. After instrumentation, the subjects rested on the ergometer for $5 \mathrm{~min}$ before autocalibration of the software (version 2.7.4). Immediately after the autocalibration, blood pressure was measured in duplicate (ProBP 3400 series; Welch Allyn, Skaneateles, NY, USA) and the mean values were fed to the software.

$\dot{V} \mathrm{O}_{2}, \mathrm{SV}$, HR and $\dot{Q}$ were recorded using 10 -s averages. On the submaximal workloads, the average of the last $2 \mathrm{~min}$ served as the steady-state values. During the incremental tests to exhaustion, the highest 30 -s average was taken as the peak value. The $a-\bar{v} \mathrm{O}_{2}$ diff was calculated as the ratio between $\dot{V} \mathrm{O}_{2}$ and $\dot{Q}$ according to the Fick equation. The peak capillary blood lactate concentration ([La $\left.]_{\text {peak }}\right)$ was measured 1 min after exhaustion (Biosen C-line; EKF Diagnostic, Cardiff, UK). The typical error for $\dot{W}_{\text {peak }}$ and $\dot{V} \mathrm{O}_{2 \text { peak }}$ measured during upright cycling (familiarisation vs pre-ET) was $3.0 \%$ and $2.9 \%$, respectively.

\section{Transthoracic echocardiography}

All subjects underwent three echocardiographic studies (pre-ET, post-ET and directly after phlebotomy) (Vivid E95; GE Vingmed Ultrasound AS, Horten, Norway) using a $2.5 \mathrm{MHz}(\mathrm{M} 5 \mathrm{Sc})$ and an active matrix 4D volume-phased array transducer. Echocardiographic views were obtained using greyscale harmonic imaging according to the recommendations of the European Association of Cardiovascular Imaging (Lang et al. 2015). Recordings were digitally stored for offline post hoc analysis (EchoPac; GE Vingmed Ultrasound AS) carried out by a blinded observer. From 2D echocardiography, left ventricular (LV) dimensions and LV diastolic function parameters were assessed. Right ventricular (RV) areas and fractional area change were assessed in the four-chamber view. Tissue Doppler was used to assess wall motion velocities at the mitral annulus level and mean values from the septal and lateral walls are reported. LV mass was calculated using Devereux' formula (Devereux et al. 1986). 3D data sets, including LV volumes and ejection fraction, were obtained using a dedicated semi-automated algorithm.

Strain analysis was performed using 2D speckle-tracking echocardiography by automatic tracking of acoustic markers on a frame-by-frame basis throughout the cardiac cycle. The endocardial borders were traced in the end-systolic frame of the 2D images from the apical 4-, 2-chamber, and apical long-axis views for the assessment of longitudinal strain. The operator manually adjusted segments where the automatic tracking failed. Peak systolic LV global longitudinal strain was averaged from $16 \mathrm{LV}$ segments. The frame rate was $61 \pm 5 \mathrm{~Hz}$.

\section{Skeletal muscle biopsy}

Biopsies ( 100-200 mg) were collected from the midportion of $m$. vastus lateralis after local anaesthesia, using the Bergström technique with manual suction $(n=10)$. The tissue was immediately dissected free from visible fat and connective tissue. An appropriate sample for immunohistochemistry was embedded in OCT (CellPath, Newtown, UK) and quickly frozen in isopentane cooled on liquid nitrogen to freezing point (approx. $-120^{\circ} \mathrm{C}$ ). Tissue allocated for Western Blotting was immediately snap-frozen in liquid nitrogen. All tissue samples were stored at $-80^{\circ} \mathrm{C}$ until further analyses.

\section{Immunohistochemistry}

Serial $8 \mu \mathrm{m}$ transverse cross-sections were cut at $-20{ }^{\circ} \mathrm{C}$ (Leica CM1860 UV; Leica Biosystems, Danvers, MA, USA), mounted on microscope slides (Superfrost Plus; Thermo Fischer Scientific, Waltham, MA, USA), air-dried and stored at $-80{ }^{\circ} \mathrm{C}$ until analyses. The sections were blocked for $60 \mathrm{~min}$ with $1 \%$ bovine serum albumin (Sigma Life Science, St Louis, MO, USA) in a phosphate-buffered saline (Sigma Life Science) and 0.05\% Tween-20 (VWR, West Chester, PA, USA) solution (PBS-t). Primary antibodies against (1) myosin heavy chain type 1 (1:500 dilution; 
BA-D5, obtained from DSHB, Iowa City, IA, USA) (Schiaffino et al. 1989) and dystrophin (1:500; ab15277; Abcam, Cambridge, UK) or (2) the endothelial marker CD31 (1:100; M0823; Dako A/S, Glostrup, Denmark) and dystrophin were diluted in the blocking solution and incubated overnight at $4{ }^{\circ} \mathrm{C}$. The sections were then washed $3 \times 10 \mathrm{~min}$ in PBS-t, incubated with secondary antibodies (1:200; Alexa Fluor 488, A11001 and A11012; Invitrogen Molecular Probes, Carlsbad, CA, USA) for $60 \mathrm{~min}$ and again washed $3 \times 10 \mathrm{~min}$ in PBS-t before mounted with Prolong Gold antifade reagent with DAPI (Life Technologies Corp., Carlsbad, CA, USA) and covered with glass. The sections were visualised under a $10 \times / 0.30 \mathrm{NA}$ air objective (UplanFL N; Olympus corp.; Tokyo, Japan) and micrographed using a high-resolution digital camera (DP72; Olympus corp.) attached to a microscope (BX61; Olympus corp.) with a fluorescence light source (X-Cite 120 PC Q; EXFO Photonic Solution Inc., ON, Mississauga, Canada). Fibre cross-sectional areas, fibre types and manual identification of capillaries were conducted and analysed using TEMA software (CheckVision, Denmark). The investigator was blinded for subject identity and time point. Capillarisation was expressed as capillaryto-fibre ratio, capillaries in contact with each fibre and capillary density (capillaries per $\mathrm{mm}^{2}$ ). A mean of $198 \pm 56$ (range 96-345) fibres were analysed for each cross-section.

\section{Protein immunoblot}

For Western blotting analyses, $\sim 60 \mathrm{mg}$ of muscle tissue was homogenised in $1 \mathrm{ml}$ T-PER (Tissue Protein Extraction Reagent, 78510; Thermo Fischer Scientific) and $20 \mu \mathrm{L}$ Halt Protease \& Phosphatase Inhibitor Cocktail (78440; Thermo Fischer Scientific). The tissue lysate was extracted, aliquoted and stored at $-80^{\circ} \mathrm{C}$ until further analyses. The protein concentration was measured using a commercial kit (Bio-Rad DC Protein Assay, 5000116; Bio-Rad Laboratories, Hercules, CA, USA) and a FLUOstar Omega microplate reader (BMG Labtech, Ortenberg, Germany). Standard Western blotting procedures were applied for quantification of citrate synthase (CS), cytochrome c oxidase subunit 4 (COXIV) and hydroxyacyl-CoA dehydrogenase (HAD): $20 \mu \mathrm{g}$ of protein was separated by $4-12 \%$ gradient Bis-Tris gels (Invitrogen, Life Technologies) for $\sim 45 \mathrm{~min}$ at $200 \mathrm{~V}$ in cold buffer (NuPage MES SDS Running Buffer; Invitrogen, Life Technologies). Proteins were subsequently transferred onto a PVDF membrane (Bio-Rad Laboratories) at $30 \mathrm{~V}$ for $90 \mathrm{~min}$ in cold buffer (NuPage Transfer Buffer; Invitrogen, Life Technologies). Membranes were blocked at room temperature for $2 \mathrm{~h}$ in a 5\% fat-free skimmed milk (Merck, Darmstadt, Germany) and 0.1\% TBS-t solution (TBS: Bio-Rad Laboratories; Tween-20: VWR). Thereafter, the membranes were divided into three pieces based on molecular weight (Protein Ladder 310005; GeneON, Ludwigshafen am Rhein,
Germany) and then incubated overnight $\left(4^{\circ} \mathrm{C}\right)$ with primary antibodies against CS (1:4000; ab96600; Abcam), COX-IV (1:2000; ab16056; Abcam) or HAD (1:8000; ab154088; Abcam). An anti-rabbit IgG (1:3000; 7074S; Cell Signaling Technology, Danvers, MA, USA) secondary antibody was applied for $1 \mathrm{~h}$ at room temperature followed by visualisation using an HRP detection system (Super Signal West Dura Extended Duration Substrate; Thermo Fischer Scientific). All antibodies were diluted in a $1 \%$ fat-free skimmed milk and $0.1 \%$ TBS-t solution. Between steps, membranes were washed in $0.1 \%$ TBS-t and TBS solutions. Chemiluminescence was detected using the ChemiDoc MP system with band-intensities quantified using Image Lab 5.1 software (Bio-Rad Laboratories). Pre- and post-samples were loaded on the same gel in duplicate, and mean values were used for statistical analysis.

\section{Statistical analyses}

Data in text and tables are presented as mean \pm standard deviation (SD) and in graphs as mean \pm standard error of the mean. The data were initially assessed for normal distribution using the D'Agostino-Pearson test. For variables only measured pre-ET and post-ET, group changes were analysed with a paired Student's $t$ test. Peak and submaximal responses measured on three time points were analysed using repeated measures ANOVA and two-way repeated measures ANOVA (workload x time point), respectively. ANOVAs were followed by the Dunnett's multiple comparisons test, comparing the control situation (pre-ET) with the post-ET and the phlebotomy trial. The alpha level was set to $\leq 0.05$ and values between $>0.05$ and $\leq 0.10$ were considered to indicate trends. GraphPad Prism 8 (GraphPad Software, CA, USA) was used for statistical analysis.

\section{Results}

\section{Body composition}

Subjects' weight was reduced by $1.4 \pm 1.8 \mathrm{~kg}(P=0.028)$ during the ET period, which was entirely accounted for by a reduction in fat mass $(-1.8 \pm 1.4 \mathrm{~kg} ; P=0.002$; Table 1$)$ as lean body mass remained unchanged $(0.1 \pm 1.3 \mathrm{~kg}$; $P=0.895)$.

\section{Haematological adaptations}

The $\mathrm{Hb}_{\text {mass }}$ increased by $24 \pm 22 \mathrm{~g}(P=0.005$; Fig. 3$)$ and BV increased by $181 \pm 288 \mathrm{ml}(P=0.044$; Table 1$)$ from preto post-ET. To re-establish pre-ET levels of $\mathrm{Hb}_{\text {mass }}$ during the phlebotomy exercise trial, $166 \pm 139 \mathrm{ml}$ of whole blood was phlebotomised, which caused the BV to be unchanged 
Table 1 Haematological variables and body composition measured before and after 10 weeks of endurance training

\begin{tabular}{|c|c|c|c|}
\hline & $\begin{array}{l}\text { Pre-training } \\
(\text { mean } \pm \text { SD })\end{array}$ & $\begin{array}{l}\text { Post-training } \\
(\text { mean } \pm \text { SD })\end{array}$ & $\%$ Change $($ mean $\pm \mathrm{SD})$ \\
\hline \multicolumn{4}{|l|}{ Body composition } \\
\hline Body weight (kg) & $74.2 \pm 12.1$ & $72.7 \pm 11.3$ & $-1.8 \pm 2.6^{*}$ \\
\hline Lean mass (kg) & $51.2 \pm 9.0$ & $51.3 \pm 9.5$ & $0.0 \pm 2.6$ \\
\hline 2-Leg lean mass (kg) & $18.0 \pm 3.9$ & $18.0 \pm 4.0$ & $-0.2 \pm 1.8$ \\
\hline Fat mass $(\mathrm{kg})$ & $20.5 \pm 4.3$ & $18.8 \pm 4.4$ & $-9.0 \pm 8.2 *$ \\
\hline \multicolumn{4}{|l|}{ Haematology } \\
\hline $\mathrm{Hb}_{\text {mass }}(\mathrm{g})$ & $795 \pm 196$ & $820 \pm 196$ & $3.3 \pm 2.9 *$ \\
\hline $\mathrm{BV}(\mathrm{ml})$ & $5098 \pm 929$ & $5279 \pm 947$ & $3.7 \pm 5.6^{*}$ \\
\hline $\mathrm{RBCV}(\mathrm{ml})$ & $2388 \pm 548$ & $2370 \pm 528$ & $-0.3 \pm 5.0$ \\
\hline $\mathrm{PV}(\mathrm{ml})$ & $2712 \pm 432$ & $2909 \pm 464$ & $7.5 \pm 9.2 *$ \\
\hline$[\mathrm{Hb}]\left(\mathrm{g} \mathrm{dl}^{-1}\right)$ & $15.5 \pm 1.5$ & $15.4 \pm 1.3$ & $-0.2 \pm 3.6$ \\
\hline Haematocrit (\%) & $46.5 \pm 3.7$ & $44.6 \pm 3.3$ & $-3.8 \pm 4.5^{*}$ \\
\hline $\operatorname{MCHC}\left(\mathrm{g} \mathrm{dl}^{-1}\right)$ & $33.3 \pm 1.8$ & $34.5 \pm 0.9$ & $4.0 \pm 4.8^{*}$ \\
\hline S-Ferritin $\left(\mu \mathrm{g}^{-1}\right)$ & $87.7 \pm 58.8$ & $86.9 \pm 52.9$ & $11.9 \pm 41.7$ \\
\hline
\end{tabular}

$N=11, B V$ blood volume, $[H b]$ haemoglobin concentration, $H b_{\text {mass }}$ haemoglobin mass, $M C H C$ mean corpuscular haemoglobin concentration, $P V$ plasma volume, $R B C V$ red blood cell volume

*Significant change from pre- to post-training $(P \leq 0.05)$

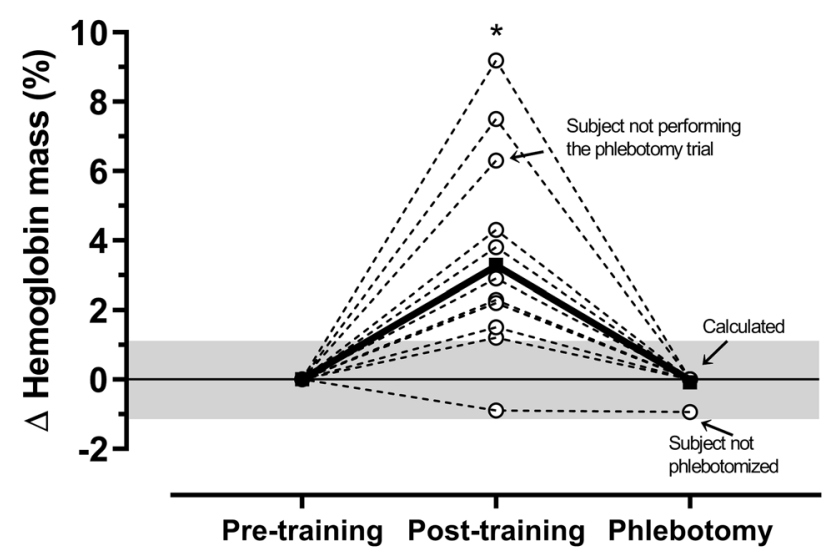

Fig. 3 Individual (white circles and dashed lines) and mean changes (black squares and solid line) in haemoglobin mass from before to after 10 weeks of endurance training. The grey area represents the percent typical error for this variable, as calculated from the duplicate measurements $(1.10 \%)$. *Significantly different from pre-training $(P=0.005) \cdot N=11-12$

compared with pre-ET levels (difference: $15 \pm 195 \mathrm{ml}$; $P=0.953)$. Due to a small increase in MCHC $(P=0.022)$ after ET (i.e. higher $\mathrm{Hb}$ concentration in the RBCs), the RBCV was decreased (difference: $-89 \pm 95 \mathrm{ml} ; P=0.020$ ) and the PV was slightly increased (difference: $104 \pm 192$; $P=0.174$ ) after phlebotomy compared with pre-ET levels.

\section{Maximal exercise tests}

After ET, $\dot{W}_{\text {peak }}$ during upright and supine cycling was increased $(12 \pm 7 \% ; P<0.001$ and $8 \pm 8 \% ; P=0.014$, respectively) and remained elevated after phlebotomy $(9 \pm 7 \% ; P=0.001$ and $7 \pm 8 \% ; P=0.048$, respectively; Fig. 4a). Similarly, $\dot{V} \mathrm{O}_{2 \text { peak }}$ increased by $11 \pm 6 \%$ $\left(0.36 \pm 0.201 \mathrm{~min}^{-1} ; P<0.001\right)$ and $10 \pm 8 \%(0.25 \pm 0.201$ $\left.\min ^{-1} ; P=0.003\right)$ during upright and supine cycling, respectively, and both remained elevated after phlebotomy (11 $\pm 4 \%$ and $11 \pm 9 \%$, respectively; both $P<0.005$; Fig. $4 \mathrm{~b}$ ). During upright cycling, $\dot{Q}_{\text {peak }}$ increased by $10 \pm 10 \%$ $\left(1.8 \pm 1.51 \mathrm{~min}^{-1} ; P=0.005\right)$ after ET and showed a trend towards remaining elevated after phlebotomy $(9 \pm 14 \%$; $P=0.081$; Fig. 4 c). During supine cycling, $\dot{Q}_{\text {peak }}$ was not changed after ET $(4 \pm 9 \%$; $P=0.376)$ but was increased after phlebotomy compared to pre-ET $(9 \pm 10 \% ; P=0.023$; Fig. 4c). This effect was driven by two outliers lowering the mean value during the post-ET assessment. The peak $\mathrm{a}-\overline{\mathrm{v}} \mathrm{O}_{2}$ diff during upright and supine cycling was unchanged after ET, both before ( $P=0.788$ and $P=0.228$, respectively) and after ( $P=0.528$ and $P=0.850$, respectively) phlebotomy (Fig. 4d).

At the three measurement time points, a similar level of exertion was evident during the incremental exercise tests, as indicated by similar peak ventilation $\left(\mathrm{VE}_{\text {peak }}\right)$, peak respiratory exchange ratio $\left(\mathrm{RER}_{\text {peak }}\right), \mathrm{HR}_{\text {peak }}$, rating of perceived exertion (RPE) and $[\mathrm{La}]_{\text {peak }}$ (Table 2 ).

\section{Submaximal exercise}

During submaximal exercise, $\mathrm{SV}$ was increased after ET both during upright $\left(F_{1.6,16.2}=3.7 ; P=0.054\right.$; see Fig. 5 for post hoc tests $)$ and supine cycling $\left(F_{1.4,14.1}=8.2 ; P=0.008\right)$, which was accompanied by a reduction in HR (upright: 
Fig. 4 Peak values of power output $(\mathbf{a})$; oxygen uptake $\left(\dot{V} \mathrm{O}_{2 \text { peak }}\right)$ (b); cardiac output $\left(\dot{Q}_{\text {peak }}\right)(\mathbf{c})$; and arteriovenous $\mathrm{O}_{2}$ difference $(\mathrm{a}-\overline{\mathrm{v}}$ $\mathrm{O}_{2}$ diff) (d) during incremental exercise tests to exhaustion before training (Pre), after training (Post) and after training and phlebotomy (Phle). Error bars indicate the standard error of the mean. *Significant change from pre-training $(P \leq 0.05)$. "Trend towards change from pre-training $(0.05<P \leq 0.10)$. $N=11$

$F_{1.4,14.4}=4.9 ; P=0.032$; supine: $\left.F_{1.4,14.0}=15.9, P<0.001\right)$. The a-v $\mathrm{O}_{2}$ diff was unchanged during submaximal exercise (upright: $F_{1.9,19.4}=1.0 ; P=0.369$; supine: $F_{1.6,16.4}=0.6$; $P=0.517)$.

\section{Cardiac morphology and function}

The LV mass increased by $13 \pm 17 \mathrm{~g}$ after ET $(P=0.027)$ and no change was observed for LV and RV chamber volumes (Table 3). Hence, an increase in LV mass-to-volume ratio (LV mass/EDV) was observed, especially after phlebotomy $(P=0.013)$, indicating concentric cardiac remodelling. All $\mathrm{LV}$ and RV diastolic and systolic function parameters were unchanged.

\section{Muscular adaptations}

ET increased the protein content of the mitochondrial enzymes CS $(P<0.001)$, COX-IV $(P=0.007)$ and HAD $(P=0.003$; Fig. 6). Fibre cross-sectional area increased (Table 4$)$, both in type I $(P=0.039)$ and type II $(P=0.023)$ muscle fibres. Despite increased cross-sectional area, the capillary density (capillaries $\mathrm{mm}^{-2}$ ) was maintained $(P=0.772)$, due to a trend towards increased capillary-tofibre ratio $(P=0.065)$.

\section{Discussion}

The primary findings of the present study are (1) the ETinduced increase in $\dot{V} \mathrm{O}_{2 \text { peak }}$ was preserved despite removing the ET-induced increases in $\mathrm{Hb}_{\text {mass }}$ and $\mathrm{BV}$ by phlebotomy. Therefore, improvements in $\dot{V} \mathrm{O}_{2 \text { peak }}$ and $\dot{Q}_{\text {peak }}$ cannot be exclusively attributed to BV expansion. (2) The improvements in $\dot{V} \mathrm{O}_{2 \text { peak }}$ were mainly accounted for by the increase in $\dot{Q}_{\text {peak }}$ and $\mathrm{SV}_{\text {peak }}$, independent of posture. (3) The ET induced concentric cardiac remodelling including an increase in LV mass, with preserved chamber dimensions measured at rest, which probably contributed to the increase in $\mathrm{SV}_{\text {peak }}$.

\section{Why was $\mathrm{VO}_{2 \text { peak }}$ maintained after reducing $\mathrm{Hb}_{\text {mass }}$ to pre-training values?}

Despite normalising $\mathrm{Hb}_{\text {mass }}$ and $\mathrm{BV}$, the ET-induced improvements in $\dot{V} \mathrm{O}_{2 \text { peak }}$ and $\dot{Q}_{\text {peak }}$ were maintained during

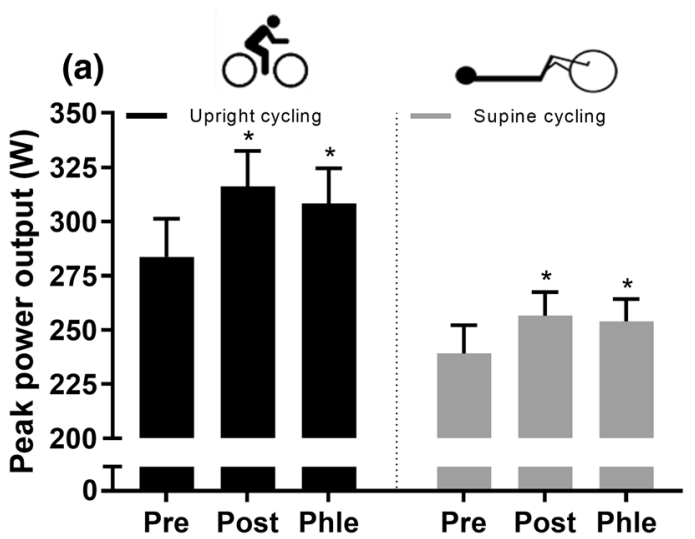

(b)

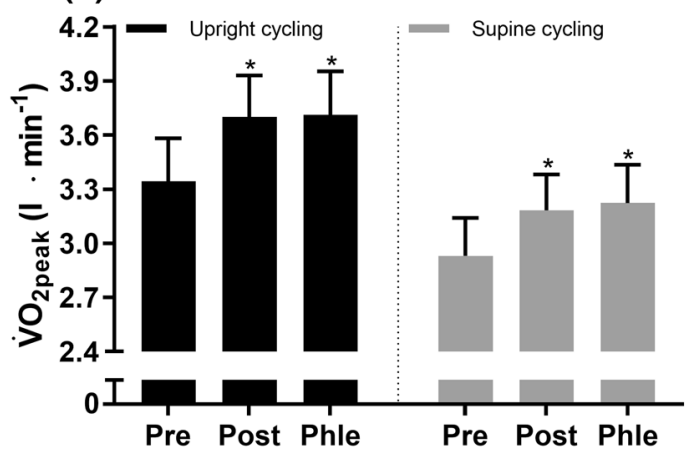

(c)

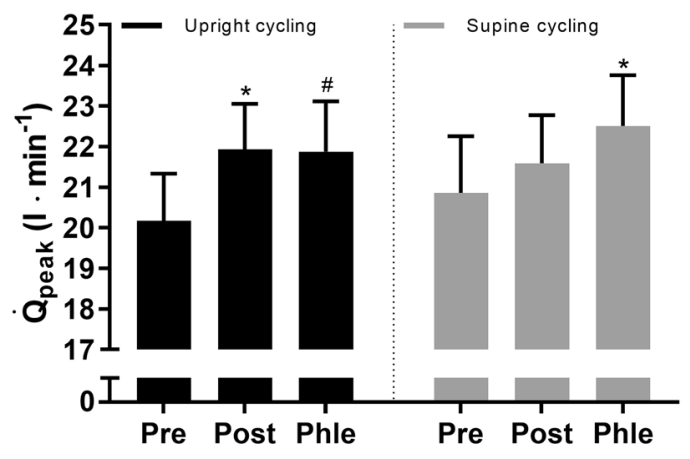

(d)

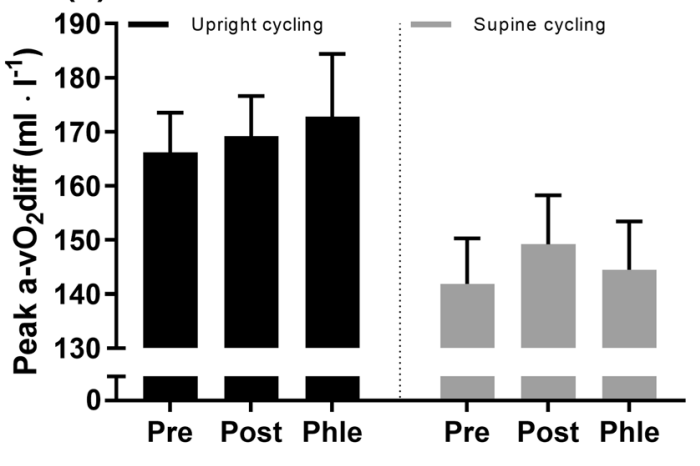


Table 2 Variables indicating the level of exertion at exhaustion

\begin{tabular}{|c|c|c|c|}
\hline Variable & $\begin{array}{l}\text { Pre-training } \\
(\text { mean } \pm \mathrm{SD})\end{array}$ & $\begin{array}{l}\text { Post-training } \\
(\text { mean } \pm \mathrm{SD})\end{array}$ & $\begin{array}{l}\text { Phlebotomy } \\
(\text { mean } \pm \text { SD) }\end{array}$ \\
\hline \multicolumn{4}{|l|}{ Upright cycling } \\
\hline $\mathrm{HR}_{\text {peak }}(\mathrm{bpm})$ & $196 \pm 7$ & $193 \pm 9$ & $193 \pm 10$ \\
\hline $\mathrm{VE}_{\text {peak }}\left(1 \mathrm{~min}^{-1}\right)$ & $146 \pm 40$ & $150 \pm 39 \#$ & $148 \pm 33$ \\
\hline $\mathrm{RER}_{\text {peak }}$ & $1.22 \pm 0.06$ & $1.21 \pm 0.05$ & $1.19 \pm 0.06$ \\
\hline$[\mathrm{La}]_{\text {peak }}\left(\mathrm{mmol} \mathrm{l}^{-1}\right)$ & $12.3 \pm 1.9$ & $12.7 \pm 2.1$ & $12.8 \pm 2.1$ \\
\hline RPE & $19.5 \pm 0.7$ & $19.5 \pm 0.7$ & $19.6 \pm 0.5$ \\
\hline \multicolumn{4}{|l|}{ Supine cycling } \\
\hline $\mathrm{HR}_{\text {peak }}(\mathrm{bpm})$ & $184 \pm 9$ & $181 \pm 12$ & $181 \pm 13$ \\
\hline $\mathrm{VE}_{\text {peak }}\left(1 \mathrm{~min}^{-1}\right)$ & $118 \pm 31$ & $123 \pm 29$ & $122 \pm 27$ \\
\hline $\mathrm{RER}_{\text {peak }}$ & $1.20 \pm 0.06$ & $1.18 \pm 0.05$ & $1.15 \pm 0.05^{*}$ \\
\hline$[\mathrm{La}]_{\text {peak }}\left(\mathrm{mmol} \mathrm{1^{-1 }}\right)$ & $10.9 \pm 2.1$ & $11.5 \pm 2.2$ & $11.1 \pm 2.8$ \\
\hline RPE & $19.5 \pm 0.8$ & $19.6 \pm 0.7$ & $19.5 \pm 0.8$ \\
\hline
\end{tabular}

$N=11, H R_{\text {peak }}$ peak heart rate (10-s average), $[\mathrm{La}]_{\text {peak }}$ peak blood lactate concentration, RPE rating of perceived exertion using the Borg scale (6-20), $R E R_{\text {peak }}$ peak respiratory exchange ratio (30-s average), $V E_{\text {peak }}$ peak ventilation (30-s average)

* Significantly different from pre-training $(P \leq 0.05)$

${ }^{\#}$ Trend towards being different from pre-training $(0.05<P \leq 0.10)$

upright cycling. This contradicts studies using a similar experimental design, which suggest that $\dot{V} \mathrm{O}_{2 \text { peak }}$ and $\dot{Q}_{\text {peak }}$ return to pre-ET levels after removing the ET-induced elevations in BV (Bonne et al. 2014) and RBCV (Montero et al. 2015a). We speculate that the discrepancies between studies originate from the magnitude of the ET-induced BV expansion. For Bonne et al. (2014) and Montero et al. (2015a), the ET-induced increases in BV were $382 \mathrm{ml}(7 \%)$ and $310 \mathrm{ml}$ (6\%), respectively, compared to $181 \mathrm{ml}(4 \%)$ in the present study. Yet, improvements in $\dot{V} \mathrm{O}_{2 \text { peak }}(9-11 \%)$ and $\dot{Q}_{\text {peak }}$ (7-10\%) during upright cycling were similar in the three studies. Thus, ET-induced increases in $\dot{V} \mathrm{O}_{2 \text { peak }}$ and $\dot{Q}_{\text {peak }}$ of this magnitude does not depend on $\mathrm{BV}$ expansion alone, and
$\dot{Q}_{\text {peak }}$ improved partly due to different mechanisms in the three studies. This is supported by increased LV mass in the present study, as opposed to no change in the study by Bonne et al. (2014), and suggests that multifactorial mechanisms explain the ET-induced increases in $\dot{Q}_{\text {peak }}$ and $\dot{V} \mathrm{O}_{2 \text { peak }}$ as suggested in classical studies (Saltin et al. 1968).

Because of the small BV withdrawal, little hypovolemia-induced impairment on venous return was likely elicited in our subjects. Supported by no reductions in $\dot{Q}$ peak,$\dot{V} \mathrm{O}_{2 \text { peak }}$ and submaximal SV during upright cycling after phlebotomy. Consequently, we were unable to test one of our main hypotheses that when $\dot{V} \mathrm{O}_{2 \text { peak }}$ and $\dot{Q}_{\text {peak }}$ during upright cycling were reversed to pre-ET levels after phlebotomy, the improvements would be preserved during supine cycling owing to the beneficial gravitational effects on venous return.

Apparently, it may be that the cardiovascular system can maintain venous return to the heart, despite small BV reductions by redistributing venous volumes through increased vasomotor activity acting on capacitance vessels. This is supported by the unchanged LV EDV, SV and peak mitral inflow velocity during early diastole from before to just after the phlebotomy procedure. There is, however, some uncertainty in extrapolating these responses measured during supine rest to upright peak exercise, where LV filling times are shorter and exert a major challenge on cardiac preload (Gledhill et al. 1994). Similarly, indications of maintained venous return despite small reductions in BV have been observed in studies examining fluid loss after heat stress and prolonged exercise (Saltin 1964; Saltin and Stenberg 1964). In those studies, a small-to-moderate reduction in PV was not sufficient to decrease $\dot{Q}_{\text {peak }}$, assessed in normothermic conditions. Thus, it was argued that an effective contribution from the muscle pump and increased vasomotor activity enabled a normal SV despite reduced BV. In contrast to small
Fig. 5 The stroke volume during upright and supine cycling as a function of heart rate during pre-training, post-training and phlebotomy exercise trials. Error bars indicate standard error of the mean. *Significant change in stroke volume from pre-training $(P \leq 0.05)$.

\#Trend towards change in stroke volume from pre-training $(0.05<P \leq 0.10) . N=11$

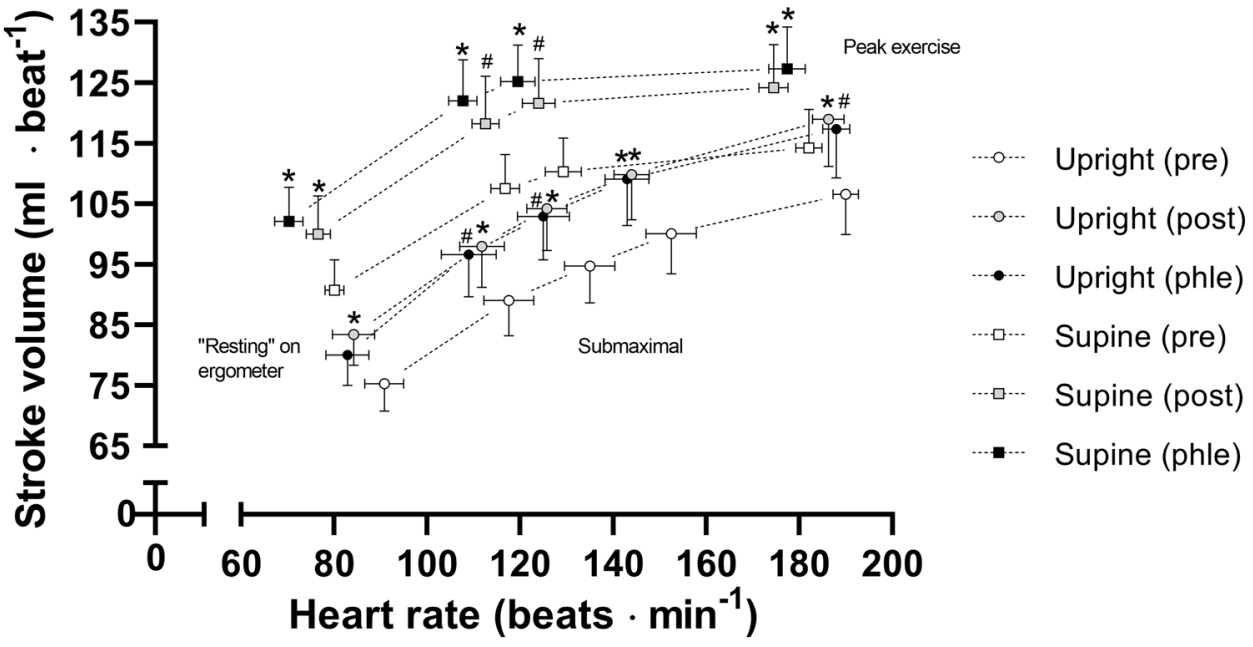


Table 3 Cardiac morphology and function measured at rest before and after 10 weeks of endurance training, as well as directly after phlebotomy

\begin{tabular}{|c|c|c|c|}
\hline Variable & $\begin{array}{l}\text { Pre-training } \\
(\text { mean } \pm \text { SD })\end{array}$ & $\begin{array}{l}\text { Post-training } \\
(\text { mean } \pm \text { SD })\end{array}$ & $\begin{array}{l}\text { Phlebotomy } \\
(\text { mean } \pm \text { SD) }\end{array}$ \\
\hline \multicolumn{4}{|l|}{ Left ventricular morphology } \\
\hline LV mass $(\mathrm{g})$ & $123 \pm 37$ & $137 \pm 37 *$ & \\
\hline IVSd (mm) & $7.4 \pm 0.8$ & $8.1 \pm 0.8$ & \\
\hline LV PWd (mm) & $7.3 \pm 0.9$ & $7.7 \pm 0.9$ & \\
\hline LV EDD (mm) & $49.1 \pm 6.5$ & $50.1 \pm 6.2$ & $49.9 \pm 6.6$ \\
\hline 3D EDV (ml) & $124 \pm 35$ & $124 \pm 40$ & $117 \pm 39$ \\
\hline 3D ESV (ml) & $49 \pm 15$ & $50 \pm 19$ & 46 \\
\hline $\mathrm{LV}$ mass-to-volume ratio $\left(\mathrm{g} \mathrm{ml}^{-1}\right)$ & $1.02 \pm 0.26$ & $1.12 \pm 0.20$ & $1.19 \pm 0.21^{*}$ \\
\hline \multicolumn{4}{|l|}{ Left ventricular systolic function } \\
\hline 3D ejection fraction (\%) & $61 \pm 3$ & $60 \pm 3$ & $61 \pm 4$ \\
\hline 3D stroke volume $(\mathrm{ml})$ & $75 \pm 21$ & $74 \pm 21$ & $71 \pm 23$ \\
\hline Global longitudinal strain (\%) & $-22.5 \pm 1.4$ & $-22.1 \pm 1.3$ & $-21.1 \pm 1.8^{\#}$ \\
\hline \multicolumn{4}{|l|}{ Left ventricular diastolic function } \\
\hline $\mathrm{E}\left(\mathrm{cm} \mathrm{s}^{-1}\right)$ & $72.9 \pm 14.5$ & $73.2 \pm 17.9$ & $69.2 \pm 13.3$ \\
\hline $\mathrm{A}\left(\mathrm{cm} \mathrm{s}^{-1}\right)$ & $47.2 \pm 5.4$ & $47.3 \pm 5.0$ & $46.2 \pm 10.4$ \\
\hline $\mathrm{E} / \mathrm{A}$ ratio & $1.6 \pm 0.4$ & $1.6 \pm 0.4$ & $1.6 \pm 0.4$ \\
\hline $\mathrm{E}^{\prime}\left(\mathrm{cm} \mathrm{s}^{-1}\right)$ & $12.5 \pm 2.1$ & $12.0 \pm 2.6$ & $11.6 \pm 1.9$ \\
\hline $\mathrm{A}^{\prime}\left(\mathrm{cm} \mathrm{s}^{-1}\right)$ & $7.8 \pm 1.1$ & $7.5 \pm 1.4$ & $7.2 \pm 1.5$ \\
\hline $\mathrm{E} / \mathrm{E}^{\prime}$ ratio & $5.8 \pm 0.6$ & $6.1 \pm 1.0$ & $6.1 \pm 1.2$ \\
\hline \multicolumn{4}{|c|}{ Right ventricular morphology and function } \\
\hline $\mathrm{RV}$ end-diastolic area $\left(\mathrm{cm}^{2}\right)$ & $19.3 \pm 4.3$ & $20.5 \pm 3.0$ & $20.3 \pm 4.1$ \\
\hline $\mathrm{RV}$ end-systolic area $\left(\mathrm{cm}^{2}\right)$ & $11.2 \pm 2.3$ & $12.0 \pm 1.8$ & $11.5 \pm 2.4$ \\
\hline $\mathrm{RV}$ fractional area change $(\%)$ & $42 \pm 4$ & $42 \pm 3$ & $43 \pm 2$ \\
\hline TAPSE $(\mathrm{cm})$ & $2.35 \pm 0.18$ & $2.31 \pm 0.22$ & $2.35 \pm 0.26$ \\
\hline \multicolumn{4}{|l|}{ Atrial morphology } \\
\hline Left atrial volume (ml) & $46 \pm 9$ & $50 \pm 8$ & $45 \pm 8$ \\
\hline Right atrial area $\left(\mathrm{cm}^{2}\right)$ & $15.7 \pm 2.9$ & $15.1 \pm 2.4$ & $15.5 \pm 2.8$ \\
\hline
\end{tabular}

LV mass, IVSd and LV PWd are reported as the mean of the post-training and phlebotomy measurements $N=11$ except for global longitudinal strain and RV parameters $(N=10), E$ and $A$ peak mitral inflow velocity during early diastole and during atrial systole, respectively, $E^{\prime}$ and $A^{\prime}$ myocardial peak velocity during early diastole and atrial systole, respectively, $E D V$ end-diastolic volume, $E S V$ end-systolic volume, $E D D$ end-diastolic diameter, $I V S d$ interventricular septum thickness in end-diastole, $L V$ left ventricular, $P W d$ posterior wall thickness in end-diastole, $R V$ right ventricular, TAPSE tricuspid annular plane systolic excursion

*Significantly different from pre-training $(P \leq 0.05)$

\#Trend towards being different from pre-training $(0.05<P \leq 0.10)$
BV losses, phlebotomy of one unit of blood $(450 \mathrm{ml})$ or more reduces $\dot{V} \mathrm{O}_{2 \text { peak }}$ by lowering venous return (Kanstrup and Ekblom 1984; Krip et al. 1997). Therefore, a certain threshold might exist, at which small reductions in BV are not detrimental to venous return, acting as a mechanism for the circulation to cope with small BV losses and PV reductions induced by, e.g., dehydration.

Although $\mathrm{Hb}_{\text {mass }}$ and $\mathrm{BV}$ were restored to pre-ET levels, transcapillary fluid shifts may occur during and after the phlebotomy procedure. The first exercise trial started $45 \mathrm{~min}$ after phlebotomy as compared with $\sim 15 \mathrm{~min}$ in the studies by Bonne et al. (2014) and Montero et al. (2015a). To obtain an indication of fluid shifts, we measured $[\mathrm{Hb}]$ repeatedly during the phlebotomy day in six of the subjects. From before $\left(15.6 \pm 1.0 \mathrm{~g} \mathrm{dl}^{-1}\right)$ to just after the phlebotomy procedure, the venous $[\mathrm{Hb}]$ was slightly decreased $\left(15.2 \pm 1.0 \mathrm{~g} \mathrm{dl}^{-1}\right.$; $P=0.19$ ), with no further change until initiation of the first $\left(15.2 \pm 1.2 \mathrm{~g} \mathrm{dl}^{-1}\right)$ and second $\left(15.2 \pm 1.1 \mathrm{~g} \mathrm{dl}^{-1}\right)$ cycling exercise trials. Therefore, at the end of, or gradually during the phlebotomy procedure, a gross movement of fluid from the interstitium to the plasma appears to have counteracted the blood withdrawal. Hence, the PV (and BV) may have been slightly higher during the phlebotomy exercise trials than reported in the present study, which may have contributed to the maintained $\dot{Q}_{\text {peak }}$. However, since the reduction in $[\mathrm{Hb}]$ exclusively occurred from before to just after the 


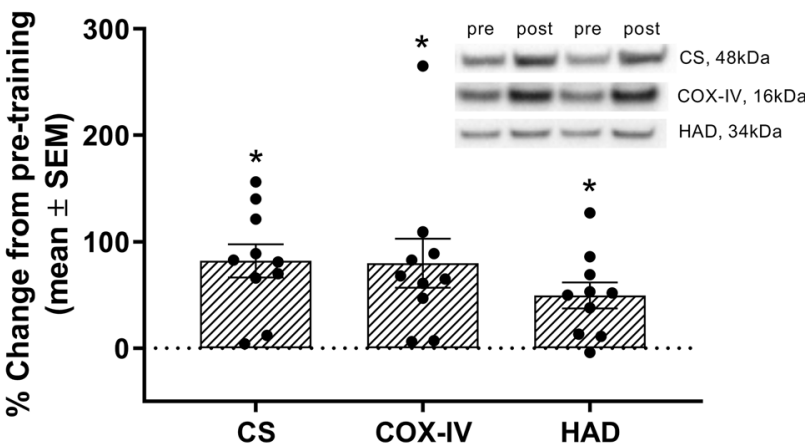

Fig. 6 The percentage change in protein content and representative Western blots for citrate synthase (CS), cytochrome c oxidase subunit 4 (COX-IV) and hydroxyacyl-CoA dehydrogenase (HAD) from preto post-training. The error bars indicate standard error of the mean. Black circles indicate individual responses. *All proteins increased from pre- to post-training $(P<0.001) . N=10$

Table 4 Muscle morphology and capillarisation before and after 10 weeks of endurance training

\begin{tabular}{|c|c|c|}
\hline Variable & $\begin{array}{l}\text { Pre-training } \\
(\text { mean } \pm S D)\end{array}$ & $\begin{array}{l}\text { Post-training } \\
(\text { mean } \pm \mathrm{SD})\end{array}$ \\
\hline \multicolumn{3}{|l|}{ Fibre size $\left(\mu \mathrm{m}^{2}\right)$} \\
\hline All fibres & $4176 \pm 818$ & $4799 \pm 1032 *$ \\
\hline Type I & $3870 \pm 468$ & $4479 \pm 720^{*}$ \\
\hline Type II & $4406 \pm 1218$ & $5027 \pm 1562^{*}$ \\
\hline \multicolumn{3}{|l|}{ Capillaries around a fibre } \\
\hline All fibres & $3.4 \pm 0.8$ & $3.8 \pm 0.8$ \\
\hline Type I & $3.4 \pm 0.7$ & $3.8 \pm 0.8$ \\
\hline Type II & $3.3 \pm 0.7$ & $3.7 \pm 1.0$ \\
\hline Capillaries $\mathrm{mm}^{-2}$ & $337 \pm 86$ & $345 \pm 67$ \\
\hline Capillary-to-fibre ratio & $1.38 \pm 0.31$ & $1.62 \pm 0.40 \#$ \\
\hline
\end{tabular}

$N=10$

*Significantly $(P \leq 0.05)$

${ }^{\#}$ Trend towards $(0.05<P \leq 0.10)$ change from pre- to post-training

phlebotomy, this mechanism has likely also affected the subjects in the Bonne et al. (2014) and Montero et al. (2015a) studies. Also, the $\mathrm{Hb}_{\text {mass }}$ was re-established to pre-ET levels independent of potential PV shifts.

We have focused on the role of BV for $\dot{Q}_{\text {peak }}$, i.e. one of the main determinants of venous return and cardiac preload. However, an ET-induced reduction in afterload through a lowering of total peripheral resistance may also increase $\dot{Q}$ peak. For instance, after ET of both legs separately, Klausen et al. (1982) found a reduction in mean arterial pressure (MAP) and total peripheral resistance that likely contributed to the increased $\dot{Q}_{\text {peak }}$ after ET. This mechanism can also have facilitated the increased $\dot{Q}_{\text {peak }}$ in the present study.

\section{The magnitude of haematological adaptations}

The changes in BV reported after 6-8 weeks ET (3-4 sessions week ${ }^{-1}$ ) typically range from 140 to $550 \mathrm{ml}$ (Bonne et al. 2014; Helgerud et al. 2007; Montero et al. 2017, 2015a; Montero and Lundby 2017b), whereas a meta-analysis reported a mean increase of $267 \mathrm{ml}$ after $\sim 15$ weeks of ET (range 1-51 weeks) (Montero and Lundby 2017a). A complex interplay of mechanisms causes the BV expansion in ET that may be affected by the training program, the training status of the subjects and their nutritional status (Montero and Lundby 2018; Sawka et al. 2000). Although our BV expansion was within the expected range, the smaller increase compared to that by Bonne et al. (2014) and Montero et al. (2015a) is unlikely caused by iron deficiency, as indicated by the normal and maintained ferritin levels. Lean body mass was maintained, indicating sufficient protein and caloric intake during the ET period. Over 10 weeks, the subjects performed 27-30 ET sessions as compared to only 18-20 sessions over 6 weeks in the studies by Bonne et al. (2014) and Montero et al. (2015a), using a similar training intensity. Hence, the training intensity and the total volume and length of the training intervention cannot explain the different findings.

\section{Central vs peripheral limitations to $\dot{\mathrm{V}}_{2 \text { peak }}$}

There were no statistically significant changes in estimated $\mathrm{a}-\overline{\mathrm{v}} \mathrm{O}_{2}$ diff from pre- to post-ET, potentially indicating no substantial contribution of peripheral adaptations to the improvements in $\dot{V} \mathrm{O}_{2 \text { peak }}$. Based on the average of all maximal exercise tests conducted pre- $(n=2$; upright and supine cycling) and post-ET ( $n=4$; before and after phlebotomy), $\dot{V} \mathrm{O}_{2 \text { peak }}$ increased by $318 \pm 147 \mathrm{ml} \mathrm{min}^{-1}$. Of this increase, the increase in $\dot{Q}_{\text {peak }}$ account for $221 \pm 202 \mathrm{ml} \mathrm{min}^{-1}$. Hence, on average, a- $\overline{\mathrm{v}} \mathrm{O}_{2}$ diff was elevated by $5 \pm 12 \mathrm{ml} \mathrm{l}^{-1}(154 \pm 22$ vs $159 \pm 25 \mathrm{ml} \mathrm{l}^{-1}$ ) and account for $30 \%$ of the increase in $\dot{V} \mathrm{O}_{2 \text { peak. }}$. Therefore, our data support that $\dot{V} \mathrm{O}_{2 \text { peak }}$ is mainly limited by convective $\mathrm{O}_{2}$ delivery (Montero et al. 2015b; Mortensen et al. 2005), but also supports calculations indicating that $70-75 \%$ of the limitations lie within the central circulation and that $25-30 \%$ are determined by peripheral factors (di Prampero 2003; di Prampero and Ferretti 1990).

$\mathrm{O}_{2}$ extraction and blood flow are interdependent. For example, by decreasing $\dot{\mathrm{Q}}_{\text {peak }}$ and leg blood flow using $\beta$-adrenergic blockade, systemic and leg a- $\overline{\mathrm{v}} \mathrm{O}_{2}$ diff increases during submaximal and maximal exercise, facilitated by increased erythrocyte capillary mean transit time (MTT) (Ekblom et al. 1972; Pawelczyk et al. 1985). In the present study, muscle fibre hypertrophy was accompanied by only a minor increase in the capillary-to-fibre ratio, causing no change in capillary density. If we calculate the capillary volume within the leg muscle mass engaged during cycling 
(Boushel et al. 2014) and subtract a non-leg blood flow of $6.51 \mathrm{~min}^{-1}$ from the total $\dot{Q}_{\text {peak }}$ (Calbet et al. 1985,2006; Lundby et al. 1985; Mortensen et al. 2005), there would be a trend towards shorter erythrocyte MTT after ET during upright peak exercise $(508 \pm 138$ vs $452 \pm 132 \mathrm{~ms}$ before and after ET, respectively). Therefore, due to reduced time for $\mathrm{O}_{2}$ unloading, peripheral adaptations such as increased muscle oxidative capacity (CS and COX-IV) may have been crucial in maintaining the pre-ET level of $a-\bar{v} \mathrm{O}_{2}$ diff. This is substantiated by a correlation between the percent change in $\mathrm{a}-\overline{\mathrm{v}}$ $\mathrm{O}_{2}$ diff during upright cycling and the percent change in CS content from before to after ET ( $r=0.73 ; n=10 ; P=0.017)$. Further improvements in $\mathrm{a}-\overline{\mathrm{v}} \mathrm{O}_{2}$ diff, at least large enough to evoke statistical significance, may likely only be detected if peripheral adaptations largely surpass the changes in $\dot{Q}_{\text {peak }}$ and peripheral blood flow.

After years of training, elite endurance athletes have a higher leg $\mathrm{O}_{2}$ extraction than untrained individuals (>90\% vs $\sim 70 \%$, respectively) (Calbet et al. 2005; Roca et al. 1985). A similar situation can be evoked by relative short periods of one-legged ET inducing robust peripheral adaptations without stimulating the central circulation, and improve leg a-v $\mathrm{O}_{2}$ diff by $5-10 \mathrm{ml} \mathrm{l}^{-1}$ (Klausen et al. 1982; Rud et al. 2012). Thus, ET improves the muscles' ability to extract $\mathrm{O}_{2}$ but may be masked by improvements in $\dot{Q}_{\text {peak }}$ and peripheral blood flow after short periods of whole-body ET (Montero et al. 2015b). Furthermore, the improvements seen after 7-8 weeks of one-legged ET by Rud et al. (2012) and Klausen et al. (1982) were in the range of 5-10 $\mathrm{ml}^{-1}$ as assessed by arterial and femoral venous blood sampling. Accordingly, small potential improvements in systemic a- $\bar{v}$ $\mathrm{O}_{2}$ diff, as indicated in the present study $\left(5 \mathrm{ml} \mathrm{l}^{-1}\right)$, may be difficult to detect when calculated from $\dot{V} \mathrm{O}_{2 \text { peak }}$ and noninvasively determined $\dot{Q}_{\text {peak }}$.

\section{Cardiac remodelling}

LV mass increased without any change in EDV. This contradicts the classic model of athletic cardiac remodelling that predicts increased EDV following ET due to the haemodynamic stimulus of volume loading on the ventricles (Morganroth et al. 1975). However, longitudinal studies demonstrate concentric remodelling at the commencement of ET, with the adaptations gradually switching into eccentric remodelling. For instance, after 3 months of ET, Arbab-Zadeh et al. (2014) found a $10 \%$ increase in LV mass-to-volume ratio before it returned to pre-ET levels after 9-12 months of ET. Therefore, with an increase in LV mass-to-volume ratio of $14 \%$ after 10 weeks of ET, our data support that the initial ET-induced cardiac remodelling is concentric (Arbab-Zadeh et al. 2014; Bjerring et al. 2019; Weiner et al. 2015).

Despite unchanged LV EDV and diastolic and systolic functional parameters at rest, the submaximal exercise
$\mathrm{SVs}$ and $\mathrm{SV}_{\text {peak }}$ were increased after ET. This indicates an increased capacity of the heart to utilise the Frank-Starling mechanism to increase SV from rest to peak exercise after ET (Crawford et al. 1985; Rerych et al. 1980). This could be due to increased chamber compliance (Arbab-Zadeh et al. 2014; Levine et al. 1991), increased filling rates (Ferguson et al. 2001; Gledhill et al. 1994), a lower rise in MAP during exercise due to reduced total peripheral resistance (Klausen et al. 1982) or a combination. Since the $\mathrm{SV}_{\text {peak }}$ was elevated even after phlebotomy, increased filling rates through expanded BV are unlikely to have made any major contribution. However, with the present experimental design, we cannot determine whether increased LV mass, enhanced venous return through other mechanisms than elevated $\mathrm{BV}$, reduced total peripheral resistance, or improved qualitative properties of the heart (e.g. contractility, compliance, faster ventricular relaxation) were facilitating the elevated $S_{\text {peak }}$ and $\dot{Q}_{\text {peak }}$.

\section{Study considerations}

Although $\mathrm{Hb}_{\text {mass }}$ and BV were restored to pre-ET levels by phlebotomy, transcapillary fluid shifts may have occurred, and it is uncertain whether BV normalisation was preserved during exercise. Some of the subjects were unfamiliar with cycling exercise before the study, and no one had tried supine cycling. Therefore, we cannot exclude the possibility that some subjects became better able to maintain venous return and cardiac filling at peak exercise after ET due to familiarisation. The findings were obtained from a small sample size. But the main finding was that the ET-induced increase in $\dot{V} \mathrm{O}_{2 \text { peak }}$ was preserved despite removing the increase in $\mathrm{Hb}_{\text {mass }}$, and this conclusion is based on methods with low typical error $\left(\dot{V} \mathrm{O}_{2 \text { peak }} 2.9 \%\right.$ and $\left.\mathrm{Hb}_{\text {mass }} 1.1 \%\right)$. Impedance cardiography is associated with a larger measurement error than the invasive gold-standard methods (Del Torto et al. 2019; Richard et al. 2001). Besides, when calculating the a-v $\mathrm{O}_{2}$ diff from $\dot{V} \mathrm{O}_{2}$ and $\dot{Q}$ inherent of its measurements errors, a larger measurement error is expected as compared with deriving a- $\overline{\mathrm{v}} \mathrm{O}_{2}$ diff using arterial and venous blood sampling.

\section{Conclusion}

Improvements in $\dot{V} \mathrm{O}_{2 \text { peak }}$ and $\dot{Q}_{\text {peak }}$ following short-term ET do not depend on $\mathrm{Hb}_{\text {mass }}$ and $\mathrm{BV}$ expansions in untrained individuals. $\dot{V} \mathrm{O}_{2 \text { peak }}$ increased primarily through increased $\dot{Q}_{\text {peak }}$ but also through a widened a- $\overline{\mathrm{v}} \mathrm{O}_{2}$ diff, explaining $\sim 70 \%$ and $\sim 30 \%$ of the improvements, respectively, and were potentially mediated by cardiac remodelling and mitochondrial biogenesis. 
Acknowledgements Open Access funding provided by Norwegian School Of Sport Sciences - The Library. The authors would like to thank the volunteers for their participation and cooperation during the study. Special thanks are given to Hege Nymo Østgaard and Marte Valde for technical assistance during the study.

Author contributions (1) Made substantial contributions to the conception or design of the work; or the acquisition, analysis, or interpretation of data; or the creation of new software used in the work; (2) drafted the work or revised it critically for important intellectual content; (3) approved the version to be published; and (4) agree to be accountable for all aspects of the work in ensuring that questions related to the accuracy or integrity of any part of the work are appropriately investigated and resolved. ØS, $\mathrm{JH}, \mathrm{CC}$ - conception and design of the experiment. ØS, MA, AWB, CC, JH, KTC, SIS-data collection. ØS, MA, AWB, KTC - analysis of data. ØS, AWB, MA, CC, SIS, JH - interpretation of data. ØS - writing the first draft. All authors-revising the manuscript. All authors have read and approved the final version of the manuscript.

Funding This study was internally funded by the Norwegian School of Sport Sciences.

\section{Compliance with ethical standards}

Conflict of interest The authors declare no conflict of interest, financial or otherwise.

Open Access This article is licensed under a Creative Commons Attribution 4.0 International License, which permits use, sharing, adaptation, distribution and reproduction in any medium or format, as long as you give appropriate credit to the original author(s) and the source, provide a link to the Creative Commons licence, and indicate if changes were made. The images or other third party material in this article are included in the article's Creative Commons licence, unless indicated otherwise in a credit line to the material. If material is not included in the article's Creative Commons licence and your intended use is not permitted by statutory regulation or exceeds the permitted use, you will need to obtain permission directly from the copyright holder. To view a copy of this licence, visit http://creativecommons.org/licenses/by/4.0/.

\section{References}

Arbab-Zadeh A, Perhonen M, Howden E, Peshock RM, Zhang R, Adams-Huet B, Haykowsky MJ, Levine BD (2014) Cardiac remodeling in response to 1 year of intensive endurance training. Circulation 130:2152-2161. https://doi.org/10.1161/circulatio naha.114.010775

Bassett DR Jr, Howley ET (2000) Limiting factors for maximum oxygen uptake and determinants of endurance performance. Med Sci Sports Exerc 32:70-84

Bjerring AW, Landgraff HE, Stokke TM, Murbraech K, Leirstein S, Aaeng A, Brun H, Haugaa KH, Hallen J, Edvardsen T, Sarvari SI (2019) The developing athlete's heart: a cohort study in young athletes transitioning through adolescence. Eur J Prev Cardiol. https://doi.org/10.1177/2047487319862061

Bonne TC, Doucende G, Fluck D, Jacobs RA, Nordsborg NB, Robach P, Walther G, Lundby C (2014) Phlebotomy eliminates the maximal cardiac output response to six weeks of exercise training. Am J Physiol Regul Integr Comp Physiol 306:752-760

Boushel R, Ara I, Gnaiger E, Helge JW, Gonzalez-Alonso J, MunckAndersen T, Sondergaard H, Damsgaard R, van Hall G, Saltin B, Calbet JA (2014) Low-intensity training increases peak arm VO2 by enhancing both convective and diffusive $\mathrm{O} 2$ delivery. Acta Physiol (Oxf) 211:122-134. https://doi.org/10.1111/apha.12258

Boushel R, Saltin B (2013) Ex vivo measures of muscle mitochondrial capacity reveal quantitative limits of oxygen delivery by the circulation during exercise. Int J Biochem Cell Biol 45:68-75. https ://doi.org/10.1016/j.biocel.2012.09.024

Bringard A, Pogliaghi S, Adami A, De Roia G, Lador F, Lucini D, Pizzinelli P, Capelli C, Ferretti G (2010) Cardiovascular determinants of maximal oxygen consumption in upright and supine posture at the end of prolonged bed rest in humans. Respir Physiol Neurobiol 172:53-62. https://doi.org/10.1016/j.resp.2010.03.018

Calbet JA, Gonzalez-Alonso J, Helge JW, Sondergaard H, MunchAndersen T, Boushel R, Saltin B (1985) Cardiac output and leg and arm blood flow during incremental exercise to exhaustion on the cycle ergometer. J Appl Physiol 103:969-978. https://doi. org/10.1152/japplphysiol.01281.2006

Calbet JA, Holmberg HC, Rosdahl H, van Hall G, Jensen-Urstad M, Saltin B (2005) Why do arms extract less oxygen than legs during exercise? Am J Physiol Regul Integr Comp Physiol 289:R14481458. https://doi.org/10.1152/ajpregu.00824.2004

Calbet JA, Lundby C, Sander M, Robach P, Saltin B, Boushel R (2006) Effects of ATP-induced leg vasodilation on VO2 peak and leg $\mathrm{O} 2$ extraction during maximal exercise in humans. Am J Physiol Regul Integr Comp Physiol 291:R447-453. https://doi. org/10.1152/ajpregu.00746.2005

Cardinale DA, Larsen FJ, Jensen-Urstad M, Rullman E, Sondergaard H, Morales-Alamo D, Ekblom B, Calbet JAL, Boushel R (2019) Muscle mass and inspired oxygen influence oxygen extraction at maximal exercise: role of mitochondrial oxygen affinity. Acta Physiol (Oxf) 225:e13110. https://doi.org/10.1111/apha.13110

Charloux A, Lonsdorfer-Wolf E, Richard R, Lampert E, OswaldMammosser M, Mettauer B, Geny B, Lonsdorfer J (2000) A new impedance cardiograph device for the non-invasive evaluation of cardiac output at rest and during exercise: comparison with the "direct" Fick method. Eur J Appl Physiol 82:313-320. https://doi. org/10.1007/s004210000226

Crawford MH, Petru MA, Rabinowitz C (1985) Effect of isotonic exercise training on left ventricular volume during upright exercise. Circulation 72:1237-1243

Del Torto A, Skattebo Ø, Hallen J, Capelli C (2019) Cardiac output with modified cardio-impedance against inert gas rebreathing during sub-maximal and maximal cycling exercise in healthy and fit subjects. Eur J Appl Physiol 119:163-170. https://doi. org/10.1007/s00421-018-4011-z

Devereux RB, Alonso DR, Lutas EM, Gottlieb GJ, Campo E, Sachs I, Reichek N (1986) Echocardiographic assessment of left ventricular hypertrophy: comparison to necropsy findings. Am J Cardiol $57: 450-458$

di Prampero PE (2003) Factors limiting maximal performance in humans. Eur J Appl Physiol 90:420-429. https://doi.org/10.1007/ s00421-003-0926-Z

di Prampero PE, Ferretti G (1990) Factors limiting maximal oxygen consumption in humans. Respir Physiol 80:113-127

Ekblom B, Goldbarg AN, Kilbom A, Astrand PO (1972) Effects of atropine and propranolol on the oxygen transport system during exercise in man. Scand J Clin Lab Invest 30:35-42. https://doi. org/10.3109/00365517209081087

Ferguson S, Gledhill N, Jamnik VK, Wiebe C, Payne N (2001) Cardiac performance in endurance-trained and moderately active young women. Med Sci Sports Exerc 33:1114-1119

Fortrat JO, Nasr O, Duvareille M, Gharib C (1998) Human cardiovascular variability, baroreflex and hormonal adaptations to a blood donation. Clin Sci (Lond) 95:269-275

Foss Ø, Hallén J (2005) Validity and stability of a computerized metabolic system with mixing chamber. Int J Sports Med 26:569-575. https://doi.org/10.1055/s-2004-821317 
Gledhill N, Cox D, Jamnik R (1994) Endurance athletes' stroke volume does not plateau: major advantage is diastolic function. Med Sci Sports Exerc 26:1116-1121

Granata C, Jamnick NA, Bishop DJ (2018) Training-induced changes in mitochondrial content and respiratory function in human skeletal muscle. Sports Med 48:1809-1828. https://doi.org/10.1007/ s40279-018-0936-y

Helgerud J, Hoydal K, Wang E, Karlsen T, Berg P, Bjerkaas M, Simonsen T, Helgesen C, Hjorth N, Bach R, Hoff J (2007) Aerobic highintensity intervals improve VO2max more than moderate training. Med Sci Sports Exerc 39:665-671. https://doi.org/10.1249/ mss.0b013e3180304570

Kanstrup IL, Ekblom B (1984) Blood volume and hemoglobin concentration as determinants of maximal aerobic power. Med Sci Sports Exerc 16:256-262

Klausen K, Andersen LB, Pelle I (1981) Adaptive changes in work capacity, skeletal muscle capillarization and enzyme levels during training and detraining. Acta Physiol Scand 113:9-16. https://doi. org/10.1111/j.1748-1716.1981.tb06854.x

Klausen K, Secher NH, Clausen JP, Hartling O, Trap-Jensen J (1982) Central and regional circulatory adaptations to one-leg training. $\mathrm{J}$ Appl Physiol 52:976-983

Krip B, Gledhill N, Jamnik V, Warburton D (1997) Effect of alterations in blood volume on cardiac function during maximal exercise. Med Sci Sports Exerc 29:1469-1476

Lang RM, Badano LP, Mor-Avi V, Afilalo J, Armstrong A, Ernande L, Flachskampf FA, Foster E, Goldstein SA, Kuznetsova T, Lancellotti P, Muraru D, Picard MH, Rietzschel ER, Rudski L, Spencer KT, Tsang W, Voigt JU (2015) Recommendations for cardiac chamber quantification by echocardiography in adults: an update from the American Society of Echocardiography and the European Association of Cardiovascular Imaging. Eur Heart J Cardiovasc Imaging 16:233-270. https://doi.org/10.1093/ehjci/jev014

Levine BD, Lane LD, Buckey JC, Friedman DB, Blomqvist CG (1991) Left ventricular pressure-volume and Frank-Starling relations in endurance athletes. Implications for orthostatic tolerance and exercise performance. Circulation 84:1016-1023

Lundby C, Robach P, Boushel R, Thomsen JJ, Rasmussen P, Koskolou M, Calbet JA (1985) Does recombinant human Epo increase exercise capacity by means other than augmenting oxygen transport? J Appl Physiol 105:581-587. https://doi.org/10.1152/japplphysiol.90484 .2008

Miller WC, Swensen T, Wallace JP (1998) Derivation of prediction equations for RV in overweight men and women. Med Sci Sports Exerc 30:322-327

Montero D, Breenfeldt-Andersen A, Oberholzer L, Haider T, Goetze JP, Meinild-Lundby AK, Lundby C (2017) Erythropoiesis with endurance training: dynamics and mechanisms. Am J Physiol Regul Integr Comp Physiol 312:894-902. https://doi.org/10.1152/ajpregu.00012 .2017

Montero D, Cathomen A, Jacobs RA, Fluck D, de Leur J, Keiser S, Bonne T, Kirk N, Lundby AK, Lundby C (2015a) Haematological rather than skeletal muscle adaptations contribute to the increase in peak oxygen uptake induced by moderate endurance training. J Physiol 593:4677-4688

Montero D, Diaz-Canestro C (2016) Endurance training and maximal oxygen consumption with ageing: Role of maximal cardiac output and oxygen extraction. Eur J Prev Cardiol 23:733-743. https://doi. org/10.1177/2047487315617118

Montero D, Diaz-Canestro C, Lundby C (2015b) Endurance training and VO2max: role of maximal cardiac output and oxygen extraction. Med Sci Sports Exerc 47:2024-2033. https://doi.org/10.1249/ mss.0000000000000640

Montero D, Lundby C (2017a) Red cell volume response to exercise training: association with aging. Scand J Med Sci Sports 27:674-683. https://doi.org/10.1111/sms. 12798
Montero D, Lundby C (2017b) Refuting the myth of non-response to exercise training: 'non-responders' do respond to higher dose of training. J Physiol 595:3377-3387. https://doi.org/10.1113/jp273480

Montero D, Lundby C (2018) Regulation of red blood cell volume with exercise training. Compr Physiol 9:149-164. https://doi.org/10.1002/ cphy.c180004

Morganroth J, Maron BJ, Henry WL, Epstein SE (1975) Comparative left ventricular dimensions in trained athletes. Ann Intern Med 82:521-524

Mortensen SP, Dawson EA, Yoshiga CC, Dalsgaard MK, Damsgaard R, Secher NH, Gonzalez-Alonso J (2005) Limitations to systemic and locomotor limb muscle oxygen delivery and uptake during maximal exercise in humans. J Physiol 566:273-285. https://doi.org/10.1113/ jphysiol.2005.086025

Pawelczyk JA, Hanel B, Pawelczyk RA, Warberg J (1985) Secher NH (1992) Leg vasoconstriction during dynamic exercise with reduced cardiac output. J Appl Physiol 73:1838-1846. https://doi. org/10.1152/jappl.1992.73.5.1838

Prommer N, Schmidt W (2007) Loss of CO from the intravascular bed and its impact on the optimised CO-rebreathing method. Eur J Appl Physiol 100:383-391. https://doi.org/10.1007/s00421-007-0439-2

Ray CA, Rea RF, Clary MP, Mark AL (1993) Muscle sympathetic nerve responses to dynamic one-legged exercise: effect of body posture. Am J Physiol 264:H1-7

Rerych SK, Scholz PM, Sabiston DC Jr, Jones RH (1980) Effects of exercise training on left ventricular function in normal subjects: a longitudinal study by radionuclide angiography. Am J Cardiol 45:244-252

Richard R, Lonsdorfer-Wolf E, Charloux A, Doutreleau S, Buchheit M, Oswald-Mammosser M, Lampert E, Mettauer B, Geny B, Lonsdorfer J (2001) Non-invasive cardiac output evaluation during a maximal progressive exercise test, using a new impedance cardiograph device. Eur J Appl Physiol 85:202-207. https://doi.org/10.1007/ s004210100458

Roca J, Agusti AG, Alonso A, Poole DC, Viegas C, Barbera JA, Rodriguez-Roisin R, Ferrer A (1985) Wagner PD (1992) Effects of training on muscle $\mathrm{O} 2$ transport at VO2max. J Appl Physiol 73:1067-1076

Rud B, Foss O, Krustrup P, Secher NH, Hallen J (2012) One-legged endurance training: leg blood flow and oxygen extraction during cycling exercise. Acta Physiol (Oxf) 205:177-185. https://doi.org/ 10.1111/j.1748-1716.2011.02383.x

Saltin B (1964) Circulatory response to submaximal and maximal exercise after thermal dehydration. J Appl Physiol 19:1125-1132. https ://doi.org/10.1152/jappl.1964.19.6.1125

Saltin B, Blomqvist G, Mitchell JH, Johnson RL Jr, Wildenthal K, Chapman CB (1968) Response to exercise after bed rest and after training. Circulation 38:71-78

Saltin B, Stenberg J (1964) Circulatory response to prolonged severe exercise. J Appl Physiol 19:833-838

Sawka MN, Convertino VA, Eichner ER, Schnieder SM, Young AJ (2000) Blood volume: importance and adaptations to exercise training, environmental stresses, and trauma/sickness. Med Sci Sports Exerc 32:332-348

Schiaffino S, Gorza L, Sartore S, Saggin L, Ausoni S, Vianello M, Gundersen K, Lomo T (1989) Three myosin heavy chain isoforms in type 2 skeletal muscle fibres. J Muscle Res Cell Motil 10:197-205. https://doi.org/10.1007/bf01739810

Schmidt W, Prommer N (2005) The optimised CO-rebreathing method: a new tool to determine total haemoglobin mass routinely. Eur J Appl Physiol 95:486-495. https://doi.org/10.1007/s00421-005-0050-3

Siebenmann C, Keiser S, Robach P, Lundby C (1985) CORP: The assessment of total hemoglobin mass by carbon monoxide rebreathing. J Appl Physiol 123:645-654. https://doi.org/10.1152/japplphysi ol.00185.2017 
Siebenmann C, Rasmussen P, Sorensen H, Zaar M, Hvidtfeldt M, Pichon A, Secher NH, Lundby C (2015) Cardiac output during exercise: a comparison of four methods. Scand J Med Sci Sports 25:e20-27. https://doi.org/10.1111/sms.12201

Warburton DE, Haykowsky MJ, Quinney HA, Blackmore D, Teo KK, Humen DP (2002) Myocardial response to incremental exercise in endurance-trained athletes: influence of heart rate, contractility and the Frank-Starling effect. Exp Physiol 87:613-622

Weiner RB, DeLuca JR, Wang F, Lin J, Wasfy MM, Berkstresser B, Stohr E, Shave R, Lewis GD, Hutter AM Jr, Picard MH, Baggish AL (2015) Exercise-induced left ventricular remodeling among competitive athletes: a phasic phenomenon. Circ Cardiovasc Imaging 8:e003651. https://doi.org/10.1161/CIRCIMAGING.115.003651
West JB (2008) Respiratory physiology : the essentials, 8th edn. Wolters Kluwer/Lippincott Williams \& Wilkins, Philadelphia

Zollei E, Paprika D, Makra P, Gingl Z, Vezendi K, Rudas L (2004) Human autonomic responses to blood donation. Auton Neurosci 110:114-120. https://doi.org/10.1016/j.autneu.2003.10.003

Publisher's Note Springer Nature remains neutral with regard to jurisdictional claims in published maps and institutional affiliations. 